\title{
Ageing of chemically modified poly(vinylidene fluoride) film: Evolution of triple carbon-carbon bonds infrared absorption
}

\author{
V.E. Zhivulin ${ }^{\mathrm{a}, \mathrm{b}}$, L.A. Pesin ${ }^{\mathrm{b}, *}$, E.A. Belenkov ${ }^{\mathrm{c}}$, V.A. Greshnyakov ${ }^{\mathrm{c}}$, N. Zlobina ${ }^{\mathrm{b}}$, \\ M. Brzhezinskaya ${ }^{\mathrm{d}, * *}$
}

\begin{abstract}
a South Ural State University, Lenin Ave. 76, 454080 Chelyabinsk, Russia
${ }^{\mathrm{b}}$ South Ural State Humanitarian Pedagogical University, Lenin Ave. 69, 454080 Chelyabinsk, Russia

c Chelyabinsk State University, Bratiev Kashirinykh Ave. 129, 454001 Chelyabinsk, Russia

${ }^{\mathrm{d}}$ Helmholtz-Zentrum Berlin für Materialien und Energie, Albert-Einstein-Str. 15, 12489 Berlin, Germany
\end{abstract}

*Corresponding author:

Prof. Dr. Leonid Pesin

South Ural State Humanitarian Pedagogical University

Lenin Ave. 69, 454080 Chelyabinsk, Russia

E-mail: pesinla@mail.ru

**Corresponding author:

Dr. habil. Maria Brzhezinskaya

Helmholtz-Zentrum Berlin für Materialien und Energie

Albert-Einstein-Str. 15, 12489 Berlin, Germany

E-mail: maria.brzhezinskaya@helmholtz-berlin.de

\begin{abstract}
The paper presents the results of the combined investigation of changes in the poly(vinylidene fluoride) (PVDF) structure caused by chemical carbonization and subsequent long-term ageing, as one of the most promising ways to synthesize the $1 D$ modification of chemically pure carbon, carbyne. For the first time, the ageing process of PVDF was monitored during extremely wide time-frame from 19 to 500000 minutes. The evolution of PVDF molecular structure was investigated experimentally by infrared and X-ray absorption spectroscopies. As a result, non-monotonic variation of triple carbon-carbon bonds infrared absorption in the course of long-term ageing was revealed, as well as new aspects of PVDF carbonization. The series of appropriate molecular complexes were modeled, for which characteristic frequencies and absorbance intensities in the IR spectra were simulated by the DFT-LDA method and applied to interpret the results of the experimental study.
\end{abstract}


Keywords: poly(vinylidene fluoride) (PVDF), carbyne, chemical carbonization, long-term ageing, IR absorption spectroscopy, density functional calculations

\section{Declarations of interest: none.}

\section{Introduction}

During recent decades one can notice an increasing number of papers devoted to the synthesis and study of new materials based on carbon (graphene, carbon nanotubes, fullerenes). Interest in carbon materials is due to their unique physical and chemical properties, promising for technical applications. Synthesis and investigation of low-dimensional carbon structures containing chain fragments [1-10] still persists to be an actual scientific problem. In this aspect, the hypothesis of the possibility of one-dimensional modification of chemically pure carbon (carbyne) is intriguing [1]. The ideal carbyne is assumed to consist of linear carbon chains in which neighboring atoms are connected by either double or alternating triple and single bonds (accordingly cumulene or polyyne types of arrangement). Chains should be packed in crystals due to van der Waals forces. The band gap for infinite carbyne in vacuum is calculated, and a wide variety of values ranging from 0.2 to $8.5 \mathrm{eV}$ have been reported [11], but the most of experimental studies reveal that carbyne-like structures have semiconducting properties [1, 12, 13]. There are different and often contradictory structural models of carbyne chains and their mutual ordering [1, 2, 4]. The discovery of crystalline carbyne in natural minerals [3] gives hope to its artificial synthesis in laboratories and open new venue in its wide industrial application.

However, up to now the ideal crystals of carbyne could not be synthesized. In the products of synthesis, coined as "carbynoids", there are not only nanoscaled fragments of linearly polymerized carbon, but also a large number of defects (non-carbonic inclusions, interchain crosslinking, etc.) $[1,2,4]$. This type of carbon was first synthesized at Nesmeyanov Institute of the USSR Academy of Sciences in 1960s [1].

One of the route of chain-like carbon nanostructures synthesis is carbonization of chain polymers having a carbon backbone, for example, poly(vinylidene fluoride) (PVDF). PVDF itself has a number of useful properties, due to which it is widely used in membrane technologies [14], electronics, medicine, acoustics, etc. $[15,16]$. Its molecules are carbon chains to each atom of which two atoms of fluorine and hydrogen are alternately attached. There are three main types of chain conformation: $\alpha, \beta$ and $\gamma$ [17]. During industrial production it is not possible to obtain PVDF with purely unique type of conformation. Depending on the prevailing conformational type, the polymer material may have different properties. For example, when $\beta$-type chains 
(plane zig-zag) dominate, the polymer has piezoelectric properties. As a rule crystalline and amorphous regions coexist in PVDF.

There are two main routes of PVDF carbonization: radiative (irradiation with photons and bombardment with microparticles of different masses and energies) [18-27] and chemical [1, 2834] ones. PVDF contains the equal number of fluorine and hydrogen atoms which are able to separate from the carbon backbone in the form of hydrogen fluoride as a result of radiative or chemical effect. This presumably allows deep but not exhaustive [26] carbonization of PVDF without destroying carbon chain-like arrangement. Adjacent carbon atoms, released from fluorine and hydrogen, can connect to each other with single and multiple bonds to form cumulene or polyyne structures [1]. Naturally interchain crosslinking becomes probable as well. But incompleteness of carbonization leaves residual $\mathrm{CF}_{2}\left(\mathrm{CH}_{2}\right)$ or/and $\mathrm{CF}(\mathrm{CH})$ species within a partially "naked" chain. These moieties may play a stabilizing role by keeping the carbonized fragments of neighboring chains apart from each other thus preventing linear carbon from an immediate collapse.

The most simple and productive method of deep carbonization of PVDF, which allows modification of sufficiently large amount of polymer, is chemical treatment. According to the known model of chemical carbonization, under the influence of a liquid dehydrofluorinating mixture fluorine and hydrogen in equal amounts are detached from the carbon backbone [1]. To date some characteristic features of a large number of chemically obtained derivatives of PVDF have been revealed [34]. For instance, the penetration depth of a dehydrofluorinating mixture in partially crystalline PVDF film is estimated and increase in the proportion of the carbon-enriched layer with the duration of dehydrofluorination is shown. The conductivity of the carbonized layer is higher than that of its polymer precursor [35], which has prospects for the synthesis of conductive and/or semiconducting nanofilms on an elastic and transparent dielectric substrate for opto- and acoustoelectronic nanodevices.

The study of the products of chemical carbonization of PVDF by NMR and IR spectroscopy showed that the increase in the duration of treatment in the dehydrofluorinating mixture elevates a ratio of the protons number to that of fluorine nuclei, despite the synchronous and monotonic decrease in the number of $\mathrm{CH}_{2}$ and $\mathrm{CF}_{2}$ groups [34]. This is due to the intense reaction of nucleophilic substitution of fluorine atoms by hydroxyl groups contained in the components of the mixture and atmospheric air. This effect prevents the formation of multiple carbon-carbon bonds inherent in carbynoid structures.

The paper presents the results of the combined investigation of changes in the poly(vinylidene fluoride) (PVDF) structure caused by chemical carbonization and subsequent long-term ageing, as one of the most promising ways to synthesize the $1 D$ modification of 
chemically pure carbon, carbyne. We succeeded to reduce joining $\mathrm{OH}$ groups to the carbon backbone by final rinsing a carbonized sample in ethanol. The evolution of its molecular structure was investigated experimentally by infrared and X-ray absorption spectroscopies. A study of long-term IR spectra shape variation during the sample ageing has shown not monotonous absorbance of the triple carbon-carbon bonds. Characteristic frequencies and absorbance intensities in the IR spectra of several model molecular complexes were simulated by the DFT-LDA method and applied to interpret the results of the experimental study.

\section{Material and experimental methods}

IR spectroscopy has been used to study the kinetics of ageing of a chemically modified PVDF (F-2M $20 \mu \mathrm{m}$ film, Plastpolymer, Russia), partially carbonized for 30 minutes in a dehydrofluorinating mixture ( 9 parts of acetone and 1 part of a saturated $\mathrm{KOH}$ solution in ethanol [30]). The carbonization treatment was carried out at room temperature. The initially transparent film darkens after chemical treatment, acquiring a brown color. After washing (preliminary with acetone and final with ethanol) and drying routines [34] a partially dehydrofluorinated sample has been strictly fixed in a holder with a rectangular window. Therefore during any measurement the same region of the sample was exposed to IR radiation.

IR spectra were systematically measured using Fourier IR spectrometer Shimadzu IRAffinity-1 in a transmission mode from 19 to $501641 \mathrm{~min}$. after chemical treatment. Thus overall 73 spectra have been obtained in the range 400-4000 $\mathrm{cm}^{-1}$. Besides we have provided for 19 extra measurements within several minutes just after registration of spectra 48 and 52 (228035 and 268296 minutes) to estimate errors in spectra parameters evaluation. These proved to be negligibly small $(<0.5 \%)$.

The X-ray absorption spectra were measured at the Russian-German beamline of the BESSY II storage ring facility at Helmholtz-Zentrum Berlin (Berlin, Germany) [37]. The samples for X-ray absorption measurements were prepared in air. The PVDF samples were 50 $\mu \mathrm{m}$ thick and $10 \times 10 \mathrm{~mm}^{2}$ in size. The films were fixed on steel sample holders to prevent the charging effect. The NEXAFS spectra were obtained by recording the total electron yield (TEY) in the mode of the drain current measurement and were measured in ultrahigh vacuum $\left(\sim 5 \times 10^{-10}\right.$ Torr). The samples were mounted at the angle of $\sim 45^{\circ}$ to the incident beam. The size of the focused spot on the sample was $\sim 200 \times 100 \mu \mathrm{m}$.

The monochromator energy resolution in the vicinity of the $\mathrm{C} 1 s \mathrm{X}$-ray absorption edge (photon energy $\sim 285 \mathrm{eV}$ ) was $\sim 70 \mathrm{meV}$. The X-ray absorption spectra were normalized to the incident photon flux. The photon energy in the range of the $\mathrm{C} 1 s \mathrm{X}$-ray absorption spectrum fine 
structure was calibrated against the energy position of the first narrow peak in the $\mathrm{C} K$-edge spectrum of highly oriented pyrolytic graphite (285.45 eV [38]).

\section{Experimental results and discussion}

C 1s near-edge X-ray absorption fine structure (NEXAFS) spectra of a pristine (not treated) PVDF film (curve 1) and those ones after chemical (curve 2) and radiative (curve 3) treatments are shown in Fig. 1. The latter spectrum shape obviously combines features typical for both the pristine material and that one carbonized with synchrotron radiation. Taking in mind high photon flux density produced in multibunch regime $(I=250 \mathrm{~mA})$ of the BESSY II storage ring $(1.7 \mathrm{GeV})$ one can assume a uniform radiative modification of polymer sample. Alternatively presence of features characteristic to polymer precursor in the spectrum of chemically treated film demonstrates just a partial carbonization.

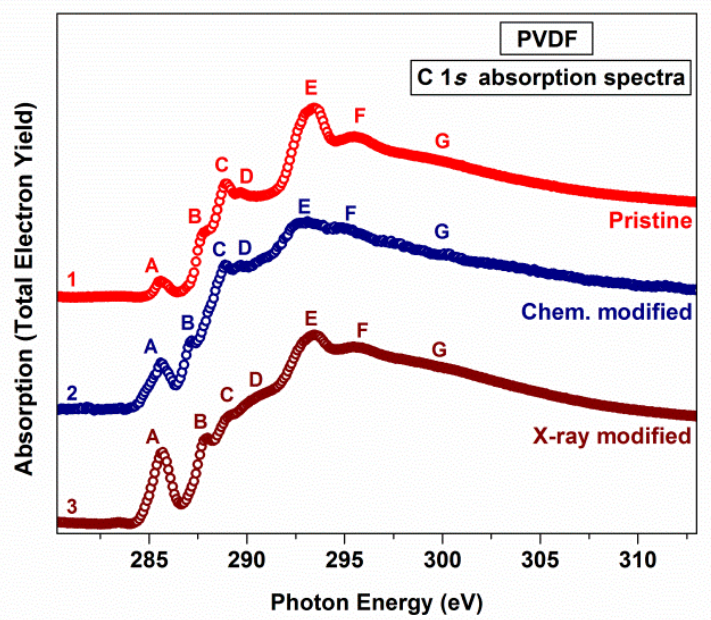

Fig. 1. C 1s NEXAFS spectra of a pristine PVDF film (curve 1) and those ones after chemical and radiative treatment (curves 2 and 3, respectively).

This conclusion is supported also by $\mathrm{CF}_{2}$ oscillations remaining in $400-750 \mathrm{~cm}^{-1}$ frequency range (Fig. 2) though their absorption is approximately a half in comparison with a precursor spectrum.

In the 2500-4000 $\mathrm{cm}^{-1}$ range IR spectrum shape of the film ageing for $19 \mathrm{~min}$. very closely resemble to that of liquid ethanol. With further ageing of the sample between 19 and 220 minutes IR absorption in this range decreases rapidly due to the evaporation of ethanol. The analysis of spectra shape shows that the rate of decrease of absorption within a broad band of stretching vibrations of $\mathrm{OH}$ groups is significantly higher to that of the $\mathrm{CH}$ band $\left(2800-3300 \mathrm{~cm}^{-}\right.$ ${ }^{1}$ ), indicating the attachment of ethoxy groups $\left(\mathrm{CH}_{3} \mathrm{CH}_{2} \mathrm{O}-\right)$ to dehydrofluorinated fragments of carbon chains. From 19 to 220 min. integral area of $\mathrm{OH}$ and $\mathrm{CH}$ bands becomes less to 12 and 2 times, correspondingly. The fact of ethoxy groups attachment is also evident from the shape of $\mathrm{CH}_{2} / \mathrm{CH}_{3}$ bands in IR spectra which persist to remain quite resemble to that of ethanol. During 
ageing between 220 and 400000 min absorption of $\mathrm{CH}_{2} / \mathrm{CH}_{3}$ bands monotonously diminishes from 50 to $40 \%$ of an initial value with a tendency for saturation from 400000 to $500000 \mathrm{~min}$.

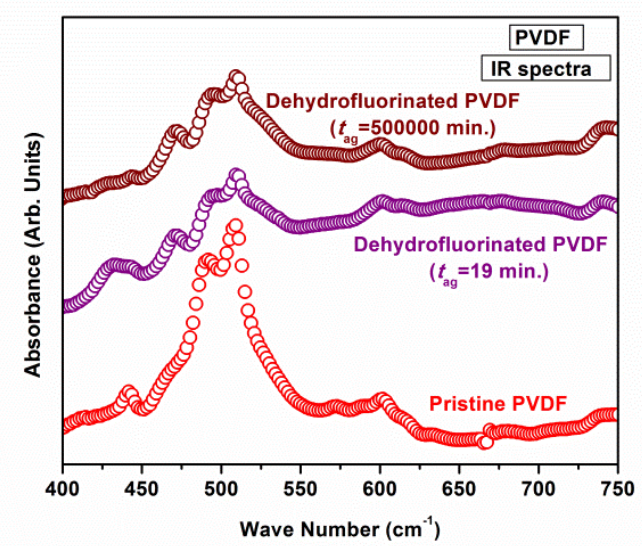

Fig. 2. Fragments of IR spectra of a pristine PVDF film and a dehydrofluorinated sample obtained at 19 and 500000 minutes after chemical treatment.

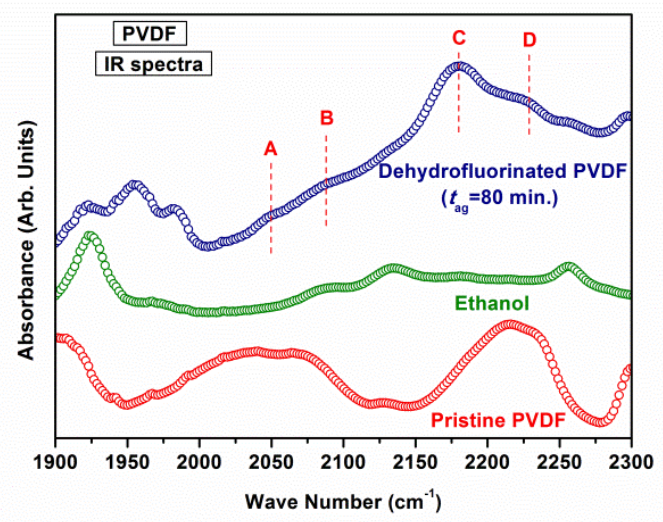

Fig. 3. Fragments of IR spectra of a pristine PVDF film, ethanol and a dehydrofluorinated sample at 80 minutes after chemical treatment.

Chemical dehydrofluorination significantly changed IR spectra in $1900-2300 \mathrm{~cm}^{-1}$ range. IR spectra of a pristine PVDF film, ethanol and of a dehydrofluorinated sample obtained at 80 min. after chemical treatment are shown in Fig. 3. Wave-like features seen in the first of them appear most probably due to interference. The latter one consists of a dominant peak at approximately $2180 \mathrm{~cm}^{-1}$ (peak $C$ ) and two and three weak shoulders consequently from higher and lower side of wave numbers. Some of these weak features are observed in IR spectra of liquid ethanol. Only three of them (near 2050, 2090 and $2220 \mathrm{~cm}^{-1}$, consequently $A, B$ and $D$ ) can be related to triple bonds oscillations. Two features in $1950-2000 \mathrm{~cm}^{-1}$ region can be attributed to IR absorption due to asymmetrical stretch oscillations of conjuncted double carboncarbon bonds in polycumulene-like fragments of dehydrofluorinated chains [36] and will be 
discussed elsewhere in the next paper. A feature with a maximum close to $\sim 1925 \mathrm{~cm}^{-1}$ is also characteristic for residual ethanol $[39,40]$ and absolutely disappears to the $220 \mathrm{~min}$. of ageing.
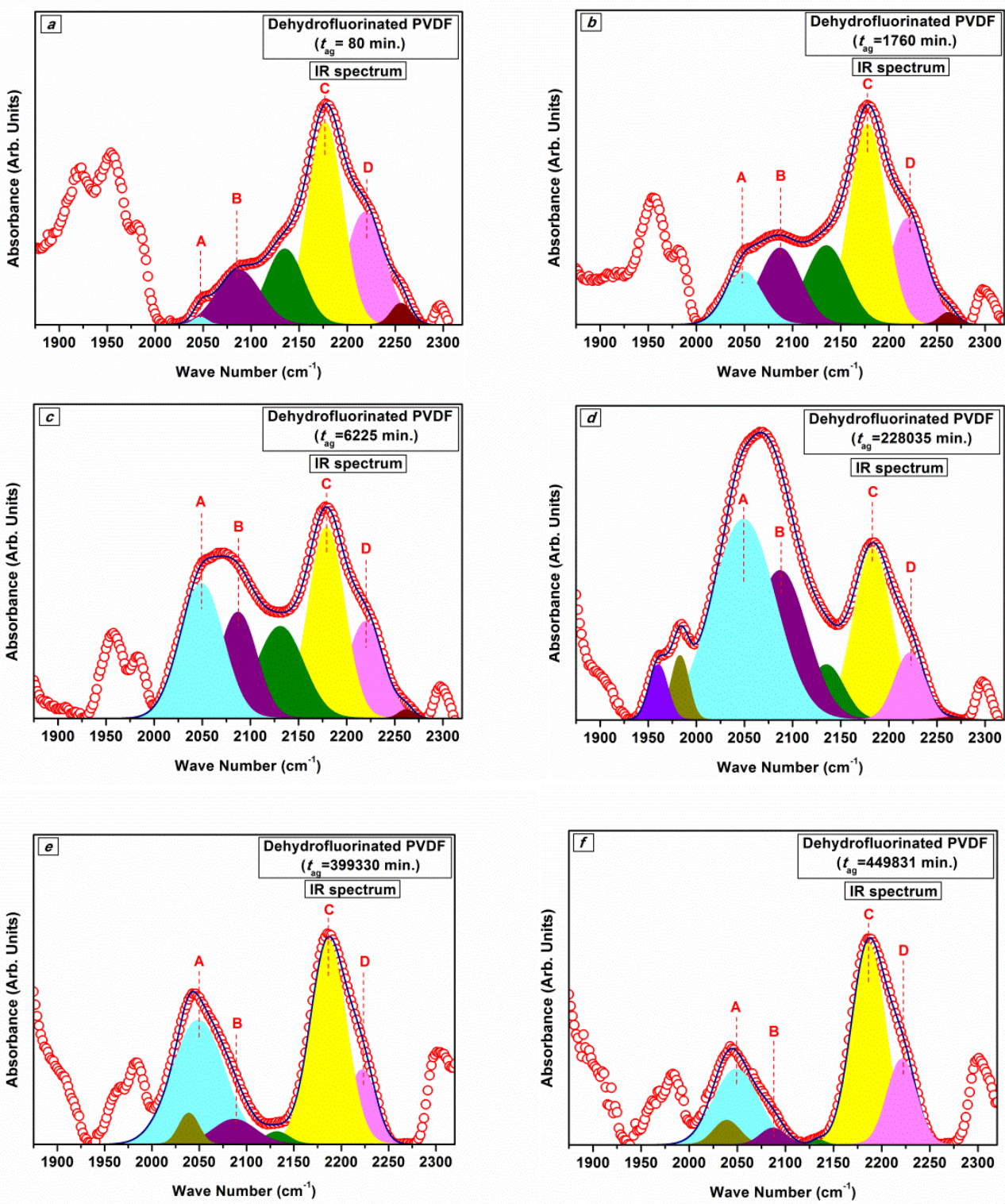

Fig. 4. Fitting of the IR spectra of the dehydrofluorinated sample obtained at $80 \mathrm{~min}$. (a), 1760 min. (b), 6225 min. (c), 228035 min. (d), 399330 min. (e) and 449831 min. (f) after chemical treatment.

All spectra obtained after background subtraction have been decomposed in 6 or 7 Gaussians in the range of $2000-2280 \mathrm{~cm}^{-1}$ to imitate the observed features. Fitting routine has been made using the Fityk software for data analysis [41].

Six examples of decomposition are presented in Figure 4,a-f. In the course of ageing features at 2049 and $2087 \mathrm{~cm}^{-1}$ (peaks $A$ and $B$ ) show the most dramatic and interesting nonmonotonic behavior. Though in common they vary quite similarly different rates of their 
elevation and decline are clearly seen in Figure 5 which shows the peaks area plotted as a function of ageing duration. Up to ageing within first $1760 \mathrm{~min}$. both peaks slowly increase and the first of them remains smaller than another. For more prolong ageing up to $9000 \mathrm{~min}$ peaks $A$ and $B$ rapidly grow. Between 1760 and 9000 min. peak $A$ grows faster than $B$ and after 5000 min. its area becomes greater than that of peak $B$. Moreover, mutual area of peaks $A$ and $B$ at 9000 min. exceeds that of peak C which dominated in spectra obtained earlier. Between 9000 and $76500 \mathrm{~min}$. areas of both peaks are more stable. Between 150000 and $200000 \mathrm{~min}$ peak $A$ demonstrates a new rising. The same but less exhibited tendency is observed in this time interval also for peaks $B$ and $C$ (for peak $C$ see Fig. 6,a). During ageing of the sample from 260000 to $450000 \mathrm{~min}$. all three discussed peaks progressively become smaller. The reduction of the peak $B$ area significantly changes the shape of the spectra and therefore becomes more apparent. Variations in peak $\mathrm{C}$ area before $260000 \mathrm{~min}$. are quite weak, and its position permanently shifts to higher frequency values (Fig. 6,b). Spectra shape practically does not vary during further ageing between 450000 and $500000 \mathrm{~min}$.

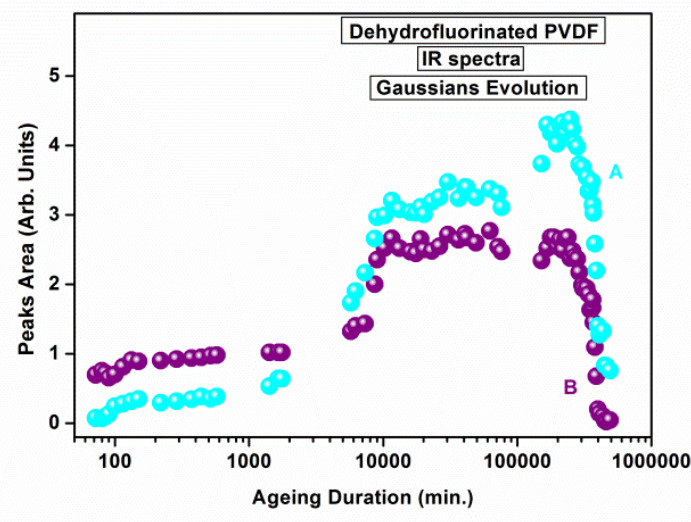

Fig. 5. Evolution of area of the two Gaussians $A$ (cyan balls) and $B$ (purple balls) centered correspondingly at 2049 and $2087 \mathrm{~cm}^{-1}$ versus duration of the dehydrofluorinated sample ageing.

Nature of IR absorption features $A-D$ in 2000-2300 $\mathrm{cm}^{-1}$ frequency range can be unambiguously attributed to triple carbon-carbon bonds oscillations [36]. On the other hand, the existence of $\mathrm{C} \equiv \mathrm{C}$ bonds is intrinsic for polyyne-like carbon chains which formation is caused by chemical dehydrofluorination of PVDF. We suppose that different positions of individual peaks in $2000-2300 \mathrm{~cm}^{-1}$ band can be explained by variation of $\mathrm{C} \equiv \mathrm{C}$ bonds environment.

Exact identification of all the observed IR spectral features is not possible now and needs further experimental and theoretical study. One may suggest a huge amount of different molecular structures in partially dehydrofluorinated film. But taking into account relatively short 
duration of chemical treatment of the sample we shall restrict our consideration only for isolated, not conjugated to each other $\mathrm{C} \equiv \mathrm{C}$ bonds. Analogously, we shall not discuss the role of defects, such as "tail-to-tail" and "head-to-head", or scissions, cross-links and branching of the chains. Given these limitations, we presume that the more likely environment of triple bound carbon atoms may be as follows:

$$
\begin{aligned}
& -\mathrm{CF}=\mathrm{CH}-\mathrm{C} \equiv \mathrm{C}-\mathrm{CF}=\mathrm{CH}- \\
& -\mathrm{C}(\mathrm{OEt})=\mathrm{CH}-\mathrm{C} \equiv \mathrm{C}-\mathrm{C}(\mathrm{OEt})=\mathrm{CH}- \\
& -\mathrm{CF}=\mathrm{CH}-\mathrm{C} \equiv \mathrm{C}-\mathrm{C}(\mathrm{OEt})=\mathrm{CH}- \\
& -\mathrm{C}(\mathrm{OEt})=\mathrm{CH}-\mathrm{C} \equiv \mathrm{C}-\mathrm{CF}=\mathrm{CH}- \\
& -\mathrm{CF}=\mathrm{CH}-\mathrm{C} \equiv \mathrm{C}-\mathrm{C}(\mathrm{O})-\mathrm{CH}- \\
& -\mathrm{C}(\mathrm{O})-\mathrm{CH}_{2}-\mathrm{C} \equiv \mathrm{C}-\mathrm{CF}=\mathrm{CH}- \\
& -\mathrm{CF}(\mathrm{OH})-\mathrm{CH}_{2}-\mathrm{C} \equiv \mathrm{C}-\mathrm{CF}=\mathrm{CH}- \\
& -\mathrm{CF}=\mathrm{CH}-\mathrm{C} \equiv \mathrm{C}-\mathrm{CF}(\mathrm{OH})-\mathrm{CH} \mathrm{H}_{2} \\
& -\mathrm{CF}=\mathrm{CH}-\mathrm{C} \equiv \mathrm{C}-\mathrm{CF}_{2}-\mathrm{CH}_{2}- \\
& -\mathrm{CF}_{2}-\mathrm{CH}_{2}-\mathrm{C} \equiv \mathrm{C}-\mathrm{CF}_{2}-\mathrm{CH}_{2}-
\end{aligned}
$$
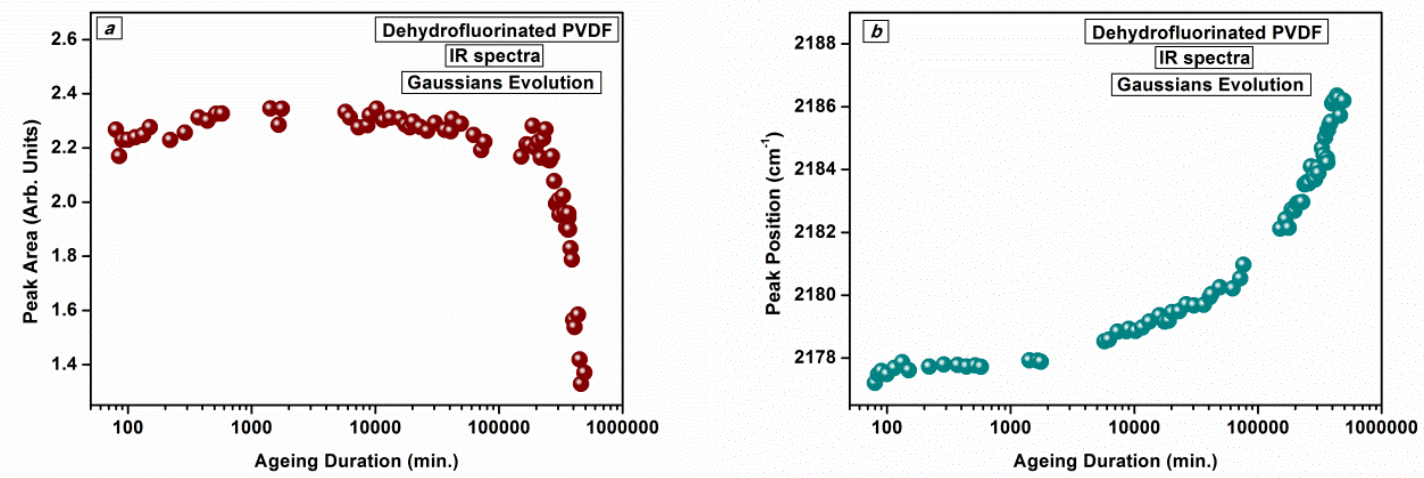

Fig. 6. Evolution of area (a) and position (b) of the Gaussian $C$ versus duration of the dehydrofluorinated sample ageing.

As was mentioned above, chemical dehydrofluorination occurs partially and not uniformly. This means different degree of carbonization in various spatial regions of the same sample. According to the commonly adopted model of chemical dehydrofluorination the process goes in two steps [1]. At the first one only fluorine-substituted polyene chain links appear. When their content becomes relatively high the last dehydrofluorination step occurs with creation of either polycumulene or polyyne carbynoid structures. As shown in [42] the latter ones are more stable. So structures " 9 " and " 10 ", while cannot be absolutely excluded from consideration, are less probable due to existence of pristine polymer fragments directly bound with triple bonds. Alternatively from the same reasons structure " $l$ " seems most probable. We believe this very 
structure is responsible for peak $C$, which dominates in spectra during first several days after dehydrofluorination.

Structure "2" corresponds to high content of ethoxy groups in the very beginning of the experiment and seems more symmetrical relative to $\mathrm{C} \equiv \mathrm{C}$ bond in comparison with " 3 " and " 4 " ones. We believe that spontaneous and random elimination of ethoxy groups is responsible for creation of quite less symmetric structures " 3 " and " 4 " and for observed non-monotonous $A$ and $B$ peaks variations. Symmetry reduction causes elevation of IR absorption and consequently spectral features $A$ and $B$. One can intuitively suppose that peaks $A$ and $B$ correspond to structures " 3 " and " 4 " because in the first one a massive ethoxy group is attached nearer to the triple bond. Different rate of peaks $A$ and $B$ variations reflects not equal stability of structures " 3 " and " 4 ". At the latest stage of the ageing experiment IR absorption in the range $2000-2300 \mathrm{~cm}^{-1}$ sharply reduces. We can assume at least two reasons for this drop. Firstly, progressive replacement of ethoxy groups due to oxidation makes environment of the triple bonds more symmetric. Secondly, oxidation can convert the triple bonds into double or single ones. Besides, oxidation can transform structure " $l$ " into structure "5" thus shifting peak $C$ to higher frequencies due to mass difference between fluorine and oxygen.

\section{Calculations}

To prove our empirical predictions, we have made an attempt for modeling of frequencies and intensities of IR features for in our opinion the most preferable cases. We have simulated IR spectra of a model molecular complex of a finite length $\mathrm{C}_{5} \mathrm{H}_{4} \mathrm{~F}_{2}$ as it is and after substitution of one or both fluorine atoms by ethoxy groups. Though polymer-like arrangement of the structures 1-10 is assumed the lengths of the studied molecular species were restricted so as to minimize computation time. Therefore only one polymer structure has been simulated. Carbon backbone of these models in any case included $-\mathrm{C}-\mathrm{C} \equiv \mathrm{C}-\mathrm{C}=\mathrm{C}$ - unit. For the $a b$ initio calculations of IR spectra of organic compounds, the density functional perturbation theory method implemented in the Quantum ESPRESSO software package [43] has been applied. Calculations were performed in the local density approximation [44] with the standard norm conserving pseudo-potentials of Troullier-Martins [45]. Integration for molecules containing from 11 to 25 atoms in Brillouin zones was carried out at $\Gamma$ point, whereas $4 \times 1 \times 1$ grids of $k$-points were used for the polymer. The wave functions were decomposed into a truncated basis set of plane waves taking into account the cutoff of kinetic energy equal to $60 \mathrm{Ry}$.

The results of calculations for the four molecular models are shown in Fig. 7. Generally they do not correspond to our preliminary qualitative predictions. 

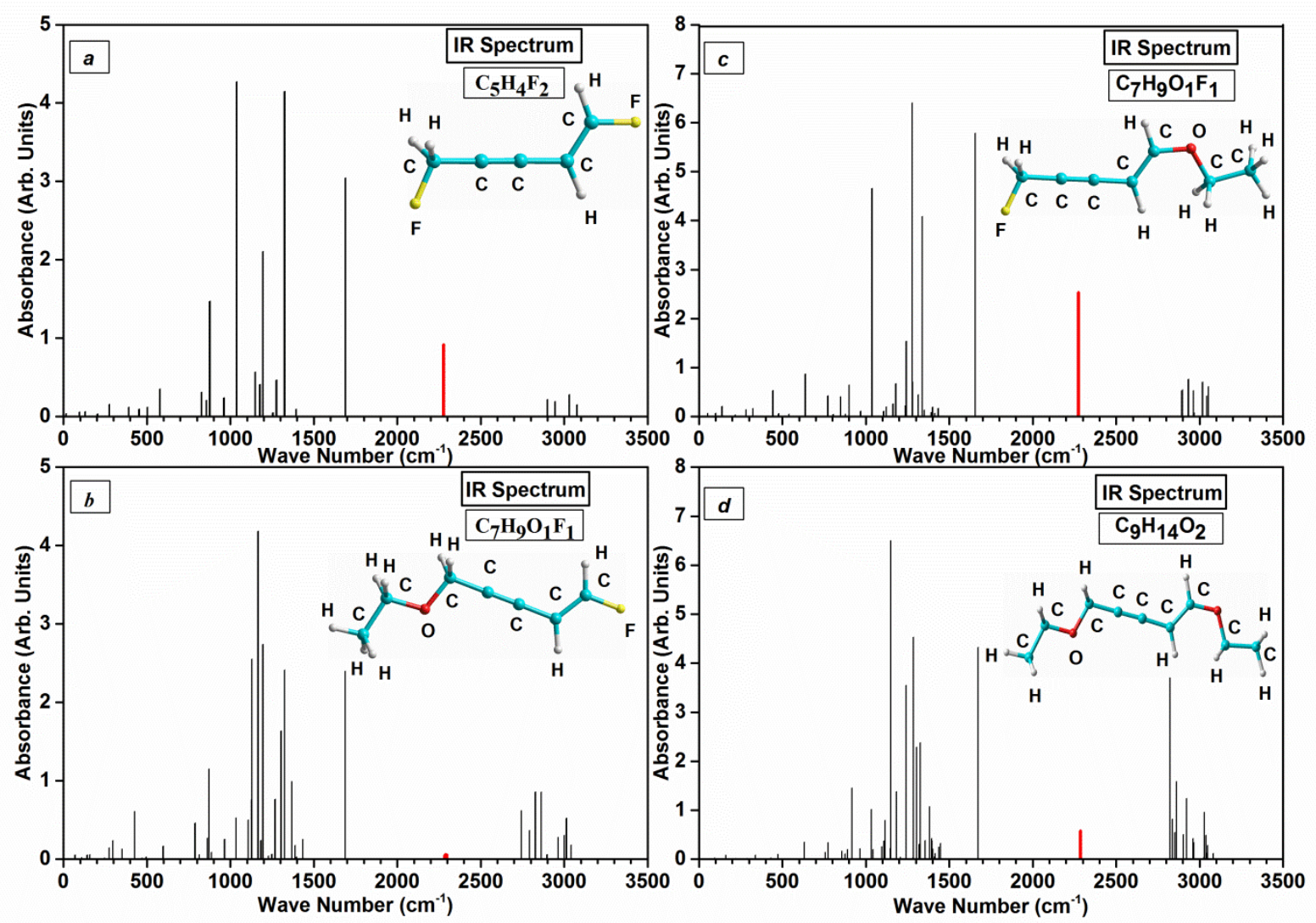

Fig. 7. Results of absorbance and frequency calculations for the four model structures (insets). The red bar corresponds to $\mathrm{C} \equiv \mathrm{C}$ vibration.

In the $\mathrm{C}_{5} \mathrm{H}_{4} \mathrm{~F}_{2}$ molecule two fluorine atoms are attached to the opposite ends of the -C$\mathrm{C} \equiv \mathrm{C}-\mathrm{C}=\mathrm{C}$ - unit (Fig. 7,a). In the calculated vibrational spectrum of this molecule, the line corresponding to the triple carbon-carbon bond oscillation frequency is at $2278.2 \mathrm{~cm}^{-1}$. This value is approximately $100 \mathrm{~cm}^{-1}$ higher than we have observed for peak $C$. The hydrocarbon molecule $\mathrm{C}_{5} \mathrm{H}_{6}$ (not shown) required to verify the calculations was obtained from the $\mathrm{C}_{5} \mathrm{H}_{4} \mathrm{~F}_{2}$ by replacing all fluorine atoms with hydrogen. In the calculated vibrational spectrum of this molecule, the line corresponding to the $\mathrm{C} \equiv \mathrm{C}$ vibration is at $2278.8 \mathrm{~cm}^{-1}$. This means that fluorine atoms do not exert practically any influence on the oscillation frequency of the $\mathrm{C} \equiv \mathrm{C}$ bonds.

The next molecule $\left(\mathrm{C}_{7} \mathrm{H}_{9} \mathrm{O}_{1} \mathrm{~F}_{1}\right)$ is obtained from $\mathrm{C}_{5} \mathrm{H}_{4} \mathrm{~F}_{2}$ if an ethoxy group replaces the fluorine atom just near $s p^{3}$ hybridized carbon atoms (Fig. 7,b). In the calculated spectrum of this molecule the line corresponding to the $\mathrm{C} \equiv \mathrm{C}$ vibration is at $2291.6 \mathrm{~cm}^{-1}$. The frequency rise as well as the intensity drop in spite of molecular mass and asymmetry elevation seems quite surprising and sharply contradicts to our preliminary assumption.

The molecule $\mathrm{C}_{7} \mathrm{H}_{9} \mathrm{O}_{1} \mathrm{~F}_{1}$ was also constructed on the basis of $\mathrm{C}_{5} \mathrm{H}_{4} \mathrm{~F}_{2}$ via replacement of the fluorine atom adjacent to $s p^{2}$ hybridized carbon atom by an ethoxy group (Fig. 7,c). In the calculated spectrum of this molecule the line corresponding to the vibration of $\mathrm{C} \equiv \mathrm{C}$ is at 2273.5 
$\mathrm{cm}^{-1}$. This value is also too high with respect to experimental ones. Besides, shift in calculated frequencies for models $\mathrm{C}_{5} \mathrm{H}_{4} \mathrm{~F}_{2}$ and $\mathrm{C}_{7} \mathrm{H}_{9} \mathrm{O}_{1} \mathrm{~F}_{1}$ is negligibly small it spite of a significant mass difference between a fluorine atom and an ethoxy group replacing it. The only thing which is in accord with our expectation is a rise in absorption due to less symmetric atomic arrangement of $\mathrm{C}_{7} \mathrm{H}_{9} \mathrm{O}_{1} \mathrm{~F}_{1}$ in comparison with $\mathrm{C}_{5} \mathrm{H}_{4} \mathrm{~F}_{2}$.

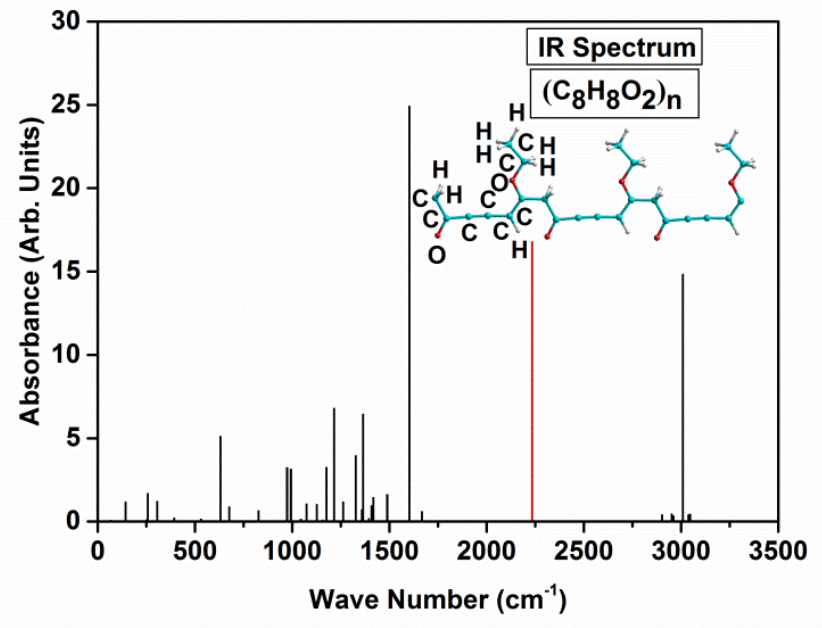

Fig. 8. Results of absorbance and frequency calculations for the model structure $\left(\mathrm{C}_{8} \mathrm{H}_{8} \mathrm{O}_{2}\right)_{\mathrm{n}}$ (inset). The red bar corresponds to $\mathrm{C} \equiv \mathrm{C}$ vibration.

The fourth molecule $\left(\mathrm{C}_{9} \mathrm{H}_{14} \mathrm{O}_{2}\right)$ is obtained from $\mathrm{C}_{5} \mathrm{H}_{4} \mathrm{~F}_{2}$ via replacement of the both fluorine atoms by ethoxy groups (Fig. 7,d). In the calculated spectrum of this molecule the $\mathrm{C} \equiv \mathrm{C}$ vibration frequency surprisingly becomes slightly higher again in spite of rise in mass and is $2286.5 \mathrm{~cm}^{-1}$. IR absorbance of this vibration becomes lower than in basic molecule $\mathrm{C}_{5} \mathrm{H}_{4} \mathrm{~F}_{2}$ presumably due to more symmetric arrangement.

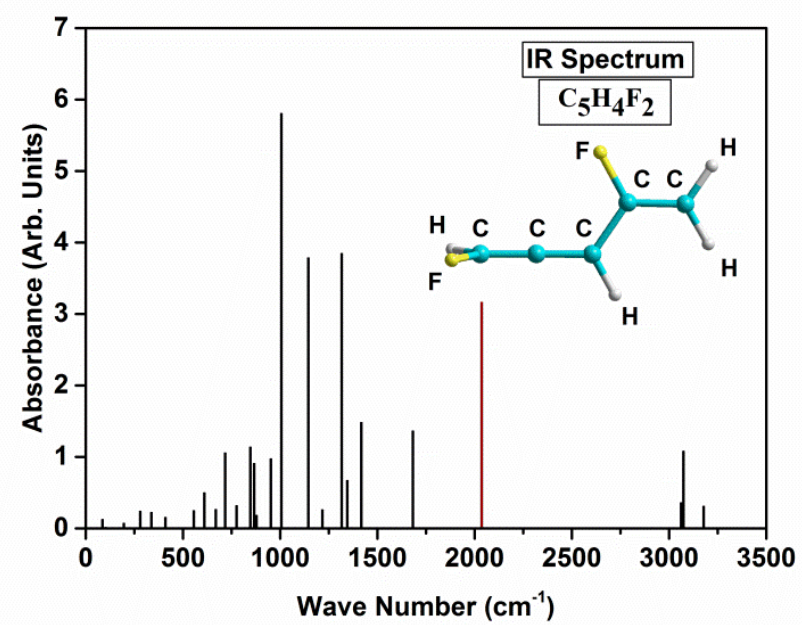

Fig. 9. Results of absorbance and frequency calculations for the $\mathrm{C}_{5} \mathrm{H}_{4} \mathrm{~F}_{2}$ molecule (inset). The red bar corresponds to $\mathrm{C}=\mathrm{C}=\mathrm{C}$ vibration. 
We have checked the validity of the Quantum ESPRESSO routine accomplished with the geometric optimization for several simple structures and found an excellent accord between computed and experimental IR data. Therefore, we believe that mentioned above striking contradictions arose due to model molecules crudity and hence their inadequacy to the real spatially extended polymeric structures.

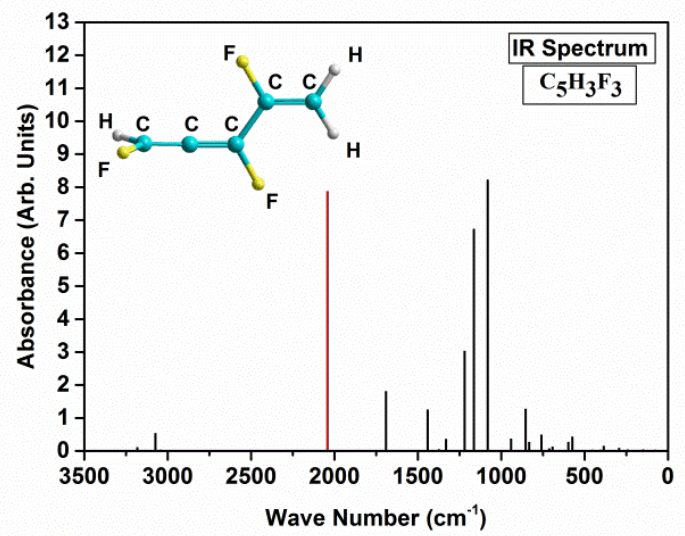

Fig. 10. Results of absorbance and frequency calculations for the $\mathrm{C}_{5} \mathrm{H}_{3} \mathrm{~F}_{3}$ molecule (inset).

The red bar corresponds to $\mathrm{C}=\mathrm{C}=\mathrm{C}$ vibration.

The last conclusion is supported by a calculation performed for the polymer $\left(\mathrm{C}_{8} \mathrm{H}_{8} \mathrm{O}_{2}\right)_{n}$. Its vibrational spectrum is shown in Fig. 8. A line of high intensity corresponding to the $\mathrm{C} \equiv \mathrm{C}$ bonds oscillation is observed at $2233.1 \mathrm{~cm}^{-1}$, i.e. much lower than in all the previous cases and hence somewhat nearer to experimental values. Another explanation can be based on the assumption of $\pi$ electrons delocalization in a long chain. Delocalization can occur when non-carbon atoms and molecular groups are removed from the chain. Indeed, calculations for the isomer $\mathrm{C}_{5} \mathrm{H}_{4} \mathrm{~F}_{2}$ containing a fragment $\mathrm{C}=\mathrm{C}=\mathrm{C}$ (Fig. 9) show the asymmetrical stretching vibration frequency of the $s p$ hybridized carbon atom equal to $2035.9 \mathrm{~cm}^{-1}$, which is a bit far from the value corresponding to the peak $A$ in the experimental IR spectra (Fig. 3). On Figure 3, the peak A can be seen at $2050 \mathrm{~cm}^{-1}$. Apparently, this is due to the fact that the ratio of fluorine and hydrogen atoms in the polymer chains of the experimentally studied samples differs from the 2:1 ratio for the $\mathrm{C}_{5} \mathrm{H}_{4} \mathrm{~F}_{2}$ molecule (the vibration frequency of the triple $\mathrm{C}-\mathrm{C}$ bond is $2035.9 \mathrm{~cm}^{-1}$ ). Calculations demonstrated that for the $\mathrm{C}_{5} \mathrm{H}_{3} \mathrm{~F}_{3}$ molecule $(\mathrm{H}: \mathrm{F}$ ratio $=1: 1)$, the vibration frequency is equal to $2043 \mathrm{~cm}^{-1}$ (Fig. 10). Obviously, with a change in the ratio of the hydrogen and fluorine atoms in the polymer chains, the vibrational frequencies of the triple bonds can vary over a rather wide range $2000-2300 \mathrm{~cm}^{-1}$, which corresponds well to the position of the peak $A$ in the experimental spectrum. This effect causes elongation of triple bonds and thus diminishes a force constant and oscillation frequencies. As a result characteristic oscillation modes vary in the 
range 2000-2300 $\mathrm{cm}^{-1}$. Besides the force constant reduction should lead to increase in mass sensitivity of oscillation frequency.

Based on our calculations, final interpretation of spectral features in the experimental IR spectra of PVDF after chemical modification and subsequent long-term ageing (see Fig. 4) is given in the Table 1.

Table 1

Interpretation of spectral features in the IR spectra of PVDF after treatment.

\begin{tabular}{|c|c|c|c|c|c|c|c|}
\hline Maximum & & $A$ & $B$ & & $C$ & $D$ & \\
\hline $\begin{array}{c}v, \mathrm{~cm}^{-1} \\
\left(t_{a g}=80 \mathrm{~min} .\right)\end{array}$ & 2048 & 2049 & 2087 & 2135 & 2177 & 2219 & 2259 \\
\hline $\begin{array}{c}S_{m}, \% \\
\left(t_{a g}=80 \mathrm{~min} .\right) \\
v, \mathrm{~cm}^{-1}\end{array}$ & 1.23 & 0.43 & 13.27 & 17.29 & 39.75 & 26.24 & 1.79 \\
\hline $\begin{array}{c}\left(t_{\text {ag. }}=449831\right. \\
\text { min. })\end{array}$ & 2037 & 2049 & 2087 & 2134 & 2186 & 2221 & - \\
\hline $\begin{array}{c}S_{m}, \% \\
\left(t_{\text {ag. }}=449831\right. \\
\text { min. })\end{array}$ & 2.73 & 29.09 & 1.36 & 0.42 & 49.36 & 17.04 & - \\
\hline Assignment & $\begin{array}{c}\text { Structure } \\
, x_{I} "\end{array}$ & $\begin{array}{c}\text { Structure } \\
, 2 “\end{array}$ & $\begin{array}{c}\text { Structure } \\
, 3 “\end{array}$ & $\begin{array}{c}\text { Ethanol+ } \\
\text { Structure } \\
, x_{2}{ }^{6}\end{array}$ & $\begin{array}{c}\text { Structure } \\
,, 1 “\end{array}$ & $\begin{array}{c}\text { Structure } \\
, x_{3}{ }^{6}\end{array}$ & Ethanol \\
\hline
\end{tabular}

\section{Conclusions}

In this work, we elucidate the poly(vinylidene fluoride) (PVDF) structure changes caused by chemical modification and subsequent subsequent long-term ageing, as one of the most promising ways to synthesize the $1 D$ modification of chemically pure carbon, carbyne, using infrared spectroscopy and high-resolution near edge X-ray absorption fine structure (NEXAFS) spectroscopy. For the first time, the ageing process of PVDF was monitored during extremely wide time-frame from 19 to 500000 minutes. As a result of such modification, the long-term not monotonous evolution of triple carbon-carbon bonds IR absorption was observed and has not been reported anywhere before. Registration in the IR spectra of triple bonds is direct evidence of the formation of polyyne fragments that are characteristic of carbyne. The experimentally observed noticeable IR intensity variations in the $2000-2300 \mathrm{~cm}^{-1}$ frequency range may be caused by the order of carbon-carbon bonds variations between 2 and 3 due to $\pi$ electrons delocalization which occurs when non-carbon atoms and molecular groups detached from the carbon backbone. 
The characteristic frequencies and absorbance intensities of the triple carbon-carbon bonds oscillations in the IR spectra of model molecular complexes was simulated by the DFTLDA method to interpret the results of the experimental study. Simulation of IR spectra showed that the modes of oscillations with frequencies in the range from 2233 to $2291 \mathrm{~cm}^{-1}$ can characterize the triple carbon-carbon bonds absorption which was observed experimentally. At the same time, there is a mode of asymmetrical stretching vibration of the conjugated cumulenic bonds with a frequency of $\sim 2025 \mathrm{~cm}^{-1}$, also characteristic for carbyne.

\section{Acknowledgements}

We thank HZB for the allocation of synchrotron radiation beamtime. The authors thank Dr. Sergey Evsyukov for fruitful discussions.

\section{References}

1. Heimann RB, Evsyukov SE, Kavan L, editors. Carbyne and carbynoid structures. Dordrecht: Kluwer Academic Publishers, 1999.

2. Luo W, Windl W. First principles study of the structure and stability of carbynes. Carbon 2009; 47:367-383. https://doi.org/10.1016/j.carbon.2008.10.017

3. Shumilova TG, Danilova YuV, Gorbunov MV, Isaenko SI. Natural monocrystal $\alpha$-Carbyne. Doklady Earth Sciences 2011; 436(1):152-154. doi:10.1134/S1028334X11010314

4. Belenkov EA, Shakhova IV. Structure of carbinoid nanotubes and carbinofullerenes. Phys Solid State 2011;53(11): 2385-2392. doi: 0.1134/S1063783411110059

5. Freitas A, Azevedo S, Kaschny JR. Structural and electronic properties of linear carbon chains encapsulated by flattened nanotubes. Physica E 2016; 84:444-453. http://dx.doi.org/10.1016/j.physe.2016.07.018

6. Buntov EA, Zatsepin AF, Guseva MB, Ponosov YuS. 2D ordered kinked carbyne chains: DFT modeling and Raman characterization. Carbon 2017;117:271-278. http://dx.doi.org/10.1016/j.carbon.2017.03.010

7. Kang C-S, Fujisawa K, Ko Y-I, Muramatsu H, Hayashi T, Endo M, Kim HJ, Lim D, Kim JH, Jung YC, Terrones M, Dresselhaus MS, Kim YA. Linear carbon chains inside multiwalled carbon nanotubes: Growth mechanism, thermal stability and electrical properties. Carbon 2016;107:217-224. https://doi.org/10.1016/j.carbon.2016.05.069

8. Andrade NF, Vasconcelos TL, Gouvea CP, Archanjo BS, Achete CA, Kim YA, Endo M, Fantini C, Dresselhaus MS, Souza Filho AG. Linear carbon chains encapsulated in multiwall carbon nanotubes: Resonance Raman spectroscopy and transmission electron microscopy studies. Carbon 2015; 90:172-180. http://dx.doi.org/10.1016/j.carbon.2015.04.001 
9. Kovriguine DA, Nikitenkova SP. Equilibrium distribution of the wave energy in a carbyne chain. Phys Solid State 2016;58(3):611-621. doi:10.1134/S1063783416030197

10. Ravagnan L, Siviero F, Lenardi C, Piseri P, Barborini E, Milani P, Casari CS, Li Bassi A, Bottani CE. Cluster-beam deposition and in situ characterization of carbyne-rich carbon films. Phys Rev Lett 2002;89:285506. doi: 10.1103/PhysRevLett.89.285506

11. Shi L, Rohringer P, Wanko M, Rubio A, Waßerroth S, Reich S, Cambré S, Wenseleers W, Ayala P, Pichler T. Electronic band gaps of confined linear carbon chains ranging from polyyne to carbyne. Physical Review Materials 2017;1(7):075601. doi: 10.1103/PhysRevMaterials.1.075601

12. Korshak VV, Kudryavtsev YuP, Khvostov VV, Guseva MB, Babaev VG, Rylova OYu. Electronic structure of carbynes studied by Auger and electron energy loss spectroscopy. Carbon 1987;25(6):735-738. doi: 10.1016/0008-6223(87)90143-6

13. Kudryavtsev YuP, Evsyukov SE, Babaev VG, Guseva MB, Khvostov VV, Krechko LM. Oriented carbyne layers. Carbon 1992;30(2):213-221. doi: 10.1016/0008-6223(92)90082-8

14. Zhang S, Shen J, Qiu X, Wend D, Zhu W. ESR and vibrational spectroscopy study on poly(vinylidene fluoride) membranes with alkaline treatment. J Power Sources 2006;153:234238. doi: 10.1016/j.jpowsour.2005.05.020

15. Kimoto A, Sugitani N. A new sensing method based on PVDF film for material identification. Meas Sci Technol 2010;21:075202. doi: 10.1088/0957-0233/21/7/075202

16. Anand SC, Kennedy JF, Miraftab M, Rajendran S, editors. Medical and healthcare textiles. Woodhead Publishing, 2010.

17. Kochervinskiy VV. Structure and properties of block poly (vinylidene fluoride) and systems based on it. Russ Chem Rev 1996;65(10):865-913. doi: 10.1070/RC1996v065n10ABEH000328 18. Le Moel A, Duraud JP, Balanzat E. Modifications of polyvinylidene fluoride (PVDF) under high energy heavy ion, $\mathrm{X}$-ray and electron irradiation studied by $\mathrm{X}$-ray photoelectron spectroscopy. Nucl Instrum Methods Phys Res 1986;B18(1-6):59-63. doi: 10.1016/S0168$583 \mathrm{X}(86) 80012-\mathrm{X}$

19. Adem EH, Bean SJ, Demanet CM, Le Moel A, Duraund JP XPS as a tool for the investigation of polymers irradiated by energetic ions. Nucl Instrum Methods Phys Res 1988;B32(1-4):182 — 185. doi: 10.1016/0168-583X(88)90206-6

20. Duca MD, Plosceanu CL, Pop T. Effect of X-rays on Poly(vinylidene fluoride) in X-ray Photoelectron Spectroscopy. J Appl Polym Sci 1998;67(13):2125-2129. doi: 10.1002/(SICI)1097-4628(19980328)67:13<2125::AID-APP2>3.0.CO;2-G 
21. Brzhezinskaya MM, Morilova VM, Baitinger EM, Evsyukov SE, Pesin LA. Study of poly(vinylidene fluoride) radiative modification using core level spectroscopy. Polym Degr Stab 2014;99:176-179 doi: 10.1016/j.polymdegradstab.2013.11.009

22. Chebotaryov SS, Volegov AA, Pesin LA, Evsyukov SE, Moskvina NA, Gribov IV, Kuznetsov VL. Modification of X-ray excited photoelectron and C KVV Auger spectra during radiative carbonization of poly(vinylidene fluoride). Physica E: Low-Dimensional Systems and Nanostructures 2007;36(2):184-189. doi: 10.1016/j.physe.2006.10.011

23. Chebotaryov SS, Baitinger EM, Volegov AA, Margamov IG, Gribov IV, Moskvina NA, Kuznetsov VL, Evsyukov SE, Pesin LA. Radiative defluorination of poly (vinylidene fluoride) under soft X-ray radiation. Rad Phys Chem 2006;75(11):2024-2028. doi: 10.1016/j.radphyschem.2005.12.051

24. Pesin, L.A., Morilova, V.M., Zherebtsov, D.A., Evsyukov, S.E. Kinetics of PVDF film degradation under electron bombardment. Polym Degrad Stab 2013;98(2):666-670. doi: 10.1016/j.polymdegradstab.2012.11.007

25. Le Moel A, Duraud JP, Lecomte C, Valin MT, Henriot M, Le Gressus C, Darnez C, Balanzat E, Demanet CM. Modifications induced in polyvinylidene fluoride by energetic ions. Nucl Instrum Methods Phys Res 1988; B32(1-4):115-119. doi: 10.1016/0168-583X(88)90192-9

26. Sidelnikova AL, Andreichuk VP, Pesin LA, Evsyukov SE, Gribov IV, Moskvina NA, Kuznetsov VL. Kinetics of radiation-induced degradation of $\mathrm{CF}_{2^{-}}$and $\mathrm{CF}$-groups in poly(vinylidene fluoride): Model refinement. Polym Degrad Stab 2014;110:308-311. doi: 10.1016/j.polymdegradstab.2014.09.009

27. Morikawa E, Choi J, Manohara HM, Ishii H, Seki K, Okudaira KK, Ueno N. Photoemission study of direct photomicromachining in poly(vinylidene fluoride). J Appl Phys 2000;87(8):40106. doi: 10.1063/1.372447

28. Ross GJ, Watts JF, Hill MP, Morrissey P. Surface modification of poly(vinylidene fluoride) by alkaline treatment. 1 . The degradation mechanism. Polymer 2000; 41:1685-1696. doi: 10.1016/S0032-3861(99)00343-2

29. Ross GJ, Watts JF, Hill MP, Morrissey P. Surface modification of poly(vinylidene fluoride) by alkaline treatment. Part 2. Process modification by the use of phase transfer catalysts. Polymer 2001;42:403 - 413. doi: 10.1016/S0032-3861(00)00328-1

30. Kudryavtsev YuP, Evsyukov SE, Babaev VG. An efficient dehydrofluorinating system for polyvinylidene fluoride. Bull Rus Acad Sci Div Chem Sci 1992;41(5):966-967. doi: 10.1007/BF00864552 
31. Margamov IG, Pesin LA, Kudryavtsev YuP, Evsyukov SE. Stability of amorphous carbynoid surface: a comparative study of photoemission intensity from the valence and core states. Appl Surf Sci 1999;148(3-4):183-188. doi: 10.1016/S0169-4332(99)00154-3

32. Mavrinskaya NA, Pesin LA, Baumgarten M, Mavrinskiy AV, Baitinger EM, Evsyukov SE. ESR studies of chemically dehydrofluorinated poly(vinylidene fluoride). Magnetic Resonance in Solids EJ 2008;10(1):31-38.

33. Zhivulin VE, Moskvina NA, Gribov IV, Andreychuk VP, Morilova VM, Khabibullina RV, Pesin LA. Study of the combined carbonization of poly(vinylidene fluoride) by X-ray photoelectron spectroscopy. J Surf Investig. X-ray, Synchrotron and Neutron Techniques 2017;11(5):927-932. doi: 10.1134/S1027451017050184

34. Zhivulin VE, Chernov VM, Osipov AA, Shtenberg MV, Evsyukov SE, Pesin LA. Analysis of the change in the concentration of fluorine and hydrogen as a result of chemical dehydrofluorination of polyvinylidene fluoride. Phys Solid State 2017;59(7):1414-1419. doi: $10.1134 / \mathrm{S} 1063783417070332$

35. Pesin LA, Chebotaryov SS, Kuvshinov AM, Bespal' II, Gribov IV, Moskvina NA, Kuznetsov VL, Evsyukov SE, Vyazovtsev AV, Kravets NS. Electron emission features of the derivatives of radiation carbonization of poly(vinylidene fluoride). J Surf Investig. X-ray, Synchrotron and Neutron Techniques 2010;4(2):214-220. doi: 10.1134/S1027451010020060

36. Alpert NL, Keiser WE, Szymanski HA IR: Theory and Practice of Infrared Spectroscopy. Springer Science \& Business Media 2012. 381 p.

37. Molodtsov SL, Fedoseenko SI, Vyalikh DV, Iossifov IE, Follath R, Gorovikov SA, Brzhezinskaya MM, Dedkov YS, Püttner R, Schmidt J-S, Adamchuk VK, Gudat W, Kaindl G. High-resolution Russian-German beamline at BESSY. Appl Phys A 2009; 94:501-505. https://doi.org/10.1007/s00339-008-4916-1

38. Brzhezinskaya MM, Muradyan VE, Vinogradov NA, Preobrajenski AB, Gudat W, Vinogradov AS. Electronic structure of fluorinated multi-walled carbon nanotubes. Phys Rev B 2009;79:155439. doi: 10.1103/PhysRevB.79.155439

39. Pogorelov V, Bulavin L, Doroshenko I, Fesjun O, Veretennikov O. The structure of liquid alcohols and the temperature dependence of vibrational bandwidth. J. Mol. Struct. 2004;708:6165. https://doi.org/10.1016/j.molstruc.2004.03.003

40. Pogorelov V, Yevglevsky A, Doroshenko I, Berezovchuk L, Zhovtobryuch Yu. Nanoscale molecular clusters and vibrational relaxation in simple alcohols. Superlattice Microst. 2008;44:571-576. https://doi.org/10.1016/j.spmi.2008.01.014

41. Wojdyr M. Fityk: a general-purpose peak fitting program. J Appl Cryst 2010;43(5):11261128. doi: $10.1107 / \mathrm{S} 0021889810030499$ 
42. Ravagnan L, Siviero F, Lenardi C, Piseri P, Barborini E, Milani P, Casari CS, Li Bassi A, Bottani CE. Cluster-beam deposition and in situ characterization of carbyne-rich carbon films. Phys Rev Lett 2002;89(28):285506. doi: 10.1103/PhysRevLett.89.285506

43. Giannozzi P, Andreussi O, Brumme T, Bunau O, Buongiorno Nardelli M, Calandra M, Car R, Cavazzoni C, Ceresoli D, Cococcioni M, Colonna N, Carnimeo I, Dal Corso A, de Gironcoli S, Delugas P, DiStasio RA, Ferretti A, Floris A, Fratesi G, Fugallo G, Gebauer R, Gerstmann U, Giustino F, Gorni T, Jia J, Kawamura M, Ko H-Y, Kokalj A, Küçükbenli E, Lazzeri M, Marsili M, Marzari N, Mauri F, Nguyen NL, Nguyen H-V, Otero-de-la-Roza A, Paulatto L, Ponce S, Rocca D, Sabatini R, Santra B, Schlipf M, Seitsonen AP, Smogunov A, Timrov I, Thonhauser T, Umari P, Vast N, Wu X, Baroni S. Advanced capabilities for materials modelling with Quantum ESPRESSO. J Phys: Condens Matter 2017;29(46):465901. doi: 10.1088/1361-648X/aa8f79

44. Perdew JP, Zunger A. Self-interaction correction to density-functional approximations for many-electron systems. Phys Rev B 1981;23(10):5048-5079. doi: 10.1103/PhysRevB.23.5048 45. Troullier N, Martins JL. Efficient pseudopotentials for plane-wave calculations. Phys Rev B 1991;43(3):1993-2006. doi: 10.1103/physrevb.43.1993 